\title{
Brain monitoring using near-infrared spectroscopy to predict outcome after cardiac arrest: a novel phenotype in a rat model of cardiac arrest
}

\author{
Ryosuke Takegawa ${ }^{1,2}$, Kei Hayashida ${ }^{1,2^{*}}$ (D), Rishabh Choudhary ${ }^{1,2}$, Daniel M. Rolston ${ }^{1,2}$ and Lance B. Becker ${ }^{1,2}$
}

\begin{abstract}
Improving neurological outcomes after cardiac arrest (CA) is the most important patient-oriented outcome for CA research. Near-infrared spectroscopy (NIRS) enables a non-invasive, real-time measurement of regional cerebral oxygen saturation. Here, we demonstrate a novel, non-invasive measurement using NIRS, termed modified cerebral oximetry index (mCOx), to distinguish the severity of brain injury after CA. We aimed to test the feasibility of this method to predict neurological outcome after asphyxial CA in rats. Our results suggest that mCOx is feasible shortly after resuscitation and can provide a surrogate measure for the severity of brain injury in a rat asphyxia CA model.
\end{abstract}

Keywords: Cardiac arrest, Cardiopulmonary resuscitation, Near-infrared spectroscopy, NIRS, Cerebral oxygen saturation, $\mathrm{rSO}_{2}$, Neurological outcome, Prognostication, Cerebral oximetry index, $\mathrm{COx}$

Letter to the Editor

Improving neurological outcomes after cardiac arrest (CA) is likely the most important patient-oriented outcome for $\mathrm{CA}$ research. Invasive brain monitoring of intracranial pressure or cerebral oxygenation is rarely used in patients with CA due to the risk of bleeding and infectious complications. Near-infrared spectroscopy (NIRS) enables a non-invasive, real-time measurement of regional cerebral oxygen saturation $\left(\mathrm{rSO}_{2}\right)$. Recent research has demonstrated a correlation between dynamic changes in mean arterial pressure (MAP) and concurrent changes in $\mathrm{rSO}_{2}$, suggesting NIRS has the potential to assess cerebral vasoreactivity $[1,2]$. It is based on assumption that changes in $\mathrm{rSO}_{2}$ are proportional to changes in cerebral blood flow over brief periods with

\footnotetext{
*Correspondence: khayashida@northwell.edu

1 Laboratory for Critical Care Physiology, Feinstein Institutes for Medical Research, Northwell Health System, Manhasset, NY, USA

${ }^{2}$ Department of Emergency Medicine, North Shore University Hospital, Northwell Health System, Manhasset, NY, USA
}

stable cerebral metabolic rate. Other studies have shown that a moving correlation coefficient between MAP and $\mathrm{rSO}_{2}$ (a value between -1 and +1 ), termed the cerebral oximetry index $(\mathrm{COx})$, was an independent predictor of outcomes in patients with CA [3, 4]. A positive COx suggests impaired autoregulatory vasoreactivity (in most studies at a threshold of $>0.3$ ), whereas a negative or near zero correlation indicates intact vasoreactivity. In most studies, COx is determined by using ICM+ software (University of Cambridge, Cambridge, UK). Although real-time, non-invasive brain monitoring plays a major role in the management of post-CA syndrome, there are no studies examining whether brain monitoring early after the return of spontaneous circulation (ROSC) enables the prognostication of neurological recovery. Establishing reliable surrogates to assess neurological recovery, which can be obtained immediately after ROSC, is an unmet medical need for developing novel strategies to improve outcomes after CA. By using a rat asphyxial CA model, we developed a modified COx

(c) The Author(s). 2021 Open Access This article is licensed under a Creative Commons Attribution 4.0 International License, which permits use, sharing, adaptation, distribution and reproduction in any medium or format, as long as you give appropriate credit to the original author(s) and the source, provide a link to the Creative Commons licence, and indicate if changes were made. The images or other third party material in this article are included in the article's Creative Commons licence, unless indicated otherwise in a credit line to the material. If material is not included in the article's Creative Commons licence and your intended use is not permitted by statutory regulation or exceeds the permitted use, you will need to obtain permission directly from the copyright holder. To view a copy of this licence, visit http://creativecommons.org/licenses/by/4.0/ The Creative Commons Public Domain Dedication waiver (http://creativecommons.org/publicdomain/zero/1.0/) applies to the data made available in this article, unless otherwise stated in a credit line to the data. 
$(\mathrm{mCOx})$ which can be calculated without the specific $\mathrm{ICM}+$ software. We aimed to test the feasibility of mCOx measured shortly after ROSC to assess neurological recovery.

TOS-QQ (TOSTEC, Co., Tokyo, Japan) measures $\mathrm{rSO}_{2}$ every second based on the Beer-Lambert law using two different wavelengths (770 and $870 \mathrm{~nm}$ ) of nearinfrared LED light. After approval by the Institutional Animal Care and Use Committees (IACUC) at Feinstein Institutes for Medical Research, Sprague-Dawley male rats $(400-500 \mathrm{~g})$ were subjected to $6 \mathrm{~min}$ or $12 \mathrm{~min}$ of vecuronium $(2 \mathrm{mg} / \mathrm{kg})$ induced-asphyxial CA followed by cardiopulmonary resuscitation (CPR) with finger chest compressions and a bolus of epinephrine $(20 \mu \mathrm{g} /$ $\mathrm{kg})$. TOS-QQ $\mathrm{Q}^{\circ}$ was attached on hair-shaved head of rats. All resuscitated rats inhaled $100 \% \mathrm{O}_{2}$ via mechanical ventilator during $\mathrm{rSO}_{2}$ measurement. The esophageal temperature was maintained at $37 \pm 0.5^{\circ} \mathrm{C}$ and end-tidal $\mathrm{CO} 2$ was controlled at $40 \pm 5 \mathrm{mmHg}$ until the end of the experiment. Neurologic function score at $24 \mathrm{~h}$ after ROSC was assessed by an investigator blinded to the experiment $(0-100$ scale; $0=$ brain death, $100=$ normal $)$. We also monitored the brain electrical activity by electroencephalogram (EEG) after ROSC. Small holes were created in the skull and bilateral stainless epidural electrodes were placed over the frontal and parietal area. To measure mCOX, digital NIRS (a number that includes one decimal place) and MAP (an integer number) signals were synchronously recorded every $1 \mathrm{~s}$. Data were directly collected to a computer and analyzed by Microsoft Excel ${ }^{\circ}$ as follows: $\mathrm{rSO}_{2}$ and MAP signals were used for a 180-s time window to calculate the Spearman correlation coefficient, which were updated every $90 \mathrm{~s}$. The mCOx was defined as a mean of 5 sequential coefficients (6-min time window) prior to the time of measurement. Given epinephrine administration affects cerebral oxygenation and metabolism immediately after $\mathrm{CPR}$ [5], $\mathrm{rSO}_{2}$ measurements were started at $15 \mathrm{~min}$ (i.e., $\mathrm{mCOx}$ recording was started at $21 \mathrm{~min}$ post-ROSC). Then, mCOx measurements were continued for $30 \mathrm{~min}$.

Neurofunction score was better in rats subjected to 6 min CA compared to 12 min CA (Fig. 1a). In terms of EEG, rats subjected to 12 min CA have a markedly longer duration from ROSC to the onset of both appearance of EEG amplitude activity ( $>5 \%$ of the basal value with no EEG activity) and continuous EEG, confirming that 12 min CA induced more severe brain damage than 6 min CA (Fig. 1b). The rats subjected to $12 \mathrm{~min} \mathrm{CA}$ had markedly higher $\mathrm{mCOx}$ values early after $\mathrm{CA}$ compared to rats subjected to 6 min CA (Fig. 1c).
A

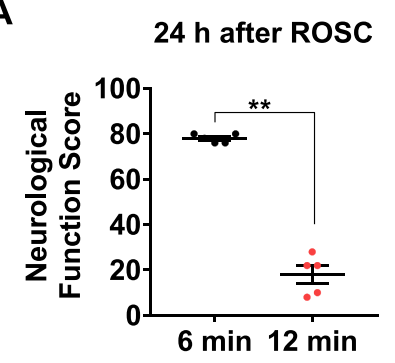

B

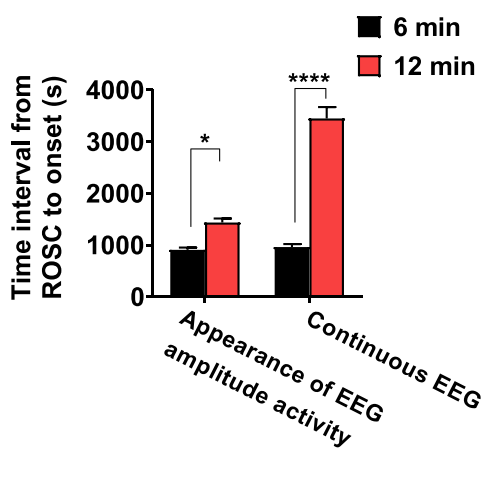

C

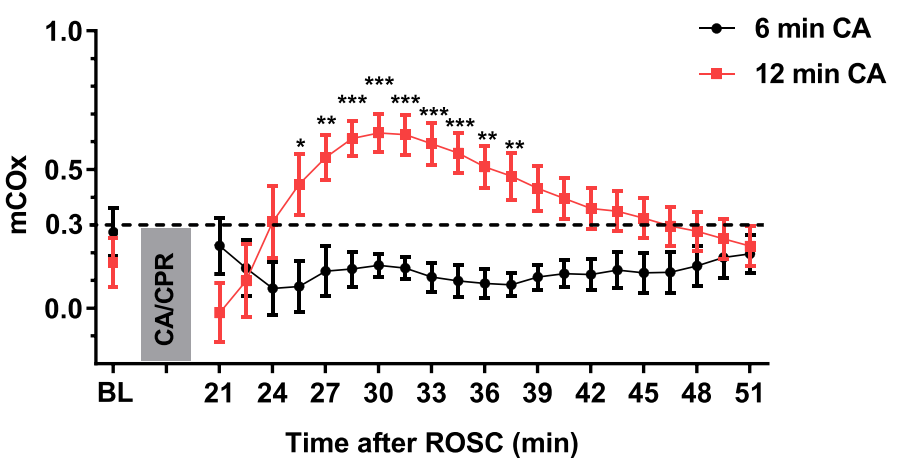

Fig. 1 a Neurological functional scores $24 \mathrm{~h}$ after cardiac arrest (CA) in rats subjected to 6 min CA and 12 min CA. Mann-Whitney $U$ test was used to test statistical difference. $n=5$ for each group. $\mathbf{b}$ Brain electrical recovery after CA measured by electroencephalogram. Two-way ANOVA followed by Sidak's corrections was used to test statistical difference. $n=3$ for each group. c Serial modified Cox (mCOx) measurements early after successful resuscitation among groups. Two-way repeated measures ANOVA followed by Sidak's corrections was used to test statistical difference. $n=12$ for each group. Data are presented as mean \pm SEM. ${ }^{*} P<.05,{ }^{* *} P<.01,{ }^{* *} P<.001,{ }^{* * *} P<.0001$ 
Our results suggest that $\mathrm{mCOx}$ measurement is feasible shortly after ROSC and can provide a surrogate measure for the severity of brain injury in rats. However, it should be noted that single measurement shortly after ROSC may not identify the time-varying aspects of the different physiological mechanisms. The exact mechanism of transient increase of mCOX early after ROSC in the 12 min CA group remains unknown. However, given that the duration of increased $\mathrm{mCOX}$ was consistent with the phase with undetectable continuous EEG activity, it can be speculated that impaired neural activity and metabolism may affect cerebral vascular reactivity and autoregulation. Further studies are warranted to determine whether the use of $\mathrm{mCOx}$ monitoring and concomitant treatment strategies can improve post-CA outcomes.

\section{Abbreviations}

CA: Cardiac arrest; NIRS: Near-infrared spectroscopy; $\mathrm{rSO}_{2}$ : Regional cerebral oxygen saturation; MAP: Mean arterial pressure; COx: Cerebral oximetry index; ROSC: Return of spontaneous circulation; mCOx: Modified cerebral oximetry index; CPR: Cardiopulmonary resuscitation;

EEG: Electroencephalogram

\section{Acknowledgements}

Not applicable

\section{Authors' contributions}

Concept and design: RT and KH. Drafting manuscript: RT and KH. Data collection and analysis: RT, KH, and CR. Critical revision of the manuscript for important intellectual content: RC, DMR, and LBB. All authors have read and approved the manuscript.

\section{Funding}

This work was supported by the internal funding from Laboratory for Critical Care Physiology at Feinstein Institutes for Medical Research.

\section{Availability of data and materials}

The datasets generated and/or analyzed during the current study are available from the corresponding author on reasonable request.

\section{Ethics approval and consent to participate}

This study was approved by the Institutional Animal Care and Use

Committees (IACUC) at Feinstein Institutes for Medical Research.

\section{Consent for publication}

Not applicable

\section{Competing interests}

The authors declare that they have no competing interests.

Received: 9 October 2020 Accepted: 26 December 2020

Published online: 07 January 2021

\section{References}

1. Lee JK, Brady KM, Mytar JO, Kibler KK, Carter EL, Hirsch KG, Hogue CW, Easley RB, Jordan LC, Smielewski P, Czosnyka M, Shaffner DH, Koehler RC. Cerebral blood flow and cerebrovascular autoregulation in a swine model of pediatric cardiac arrest and hypothermia. Critical Care Medicine. 2011;39: 2337-45.

2. Sekhon MS, Smielewski P, Bhate TD, Brasher PM, Foster D, Menon DK, Gupta AK, Czosnyka M, Henderson WR, Gin K, Wong G, Griesdale DE. Using the relationship between brain tissue regional saturation of oxygen and mean arterial pressure to determine the optimal mean arterial pressure in patients following cardiac arrest: a pilot proof-of-concept study. Resuscitation. 2016; 106:120-5.
3. Pham P, Bindra J, Chuan A, Jaeger M, Aneman A. Are changes in cerebrovascular autoregulation following cardiac arrest associated with neurological outcome? Results of a pilot study. Resuscitation. 2015;96:192-8. 4. Ameloot K, Genbrugge C, Meex I, Jans F, Boer W, Vander Laenen M, Ferdinande B, Mullens W, Dupont M, Dens J, DeDeyne C. An observational near-infrared spectroscopy study on cerebral autoregulation in post-cardiac arrest patients: time to drop 'one-size-fits-all' hemodynamic targets? Resuscitation. 2015;90:121-6.

5. Nosrati R, Lin S, Mohindra R, Ramadeen A, Toronov V, Dorian P. Study of the effects of epinephrine on cerebral oxygenation and metabolism during cardiac arrest and resuscitation by hyperspectral near-infrared spectroscopy. Critical Care Medicine. 2019;47:e349-57.

\section{Publisher's Note}

Springer Nature remains neutral with regard to jurisdictional claims in published maps and institutional affiliations.
Ready to submit your research? Choose BMC and benefit from:

- fast, convenient online submission

- thorough peer review by experienced researchers in your field

- rapid publication on acceptance

- support for research data, including large and complex data types

- gold Open Access which fosters wider collaboration and increased citations

- maximum visibility for your research: over $100 \mathrm{M}$ website views per year

At BMC, research is always in progress.

Learn more biomedcentral.com/submissions 